\title{
Editorial
}

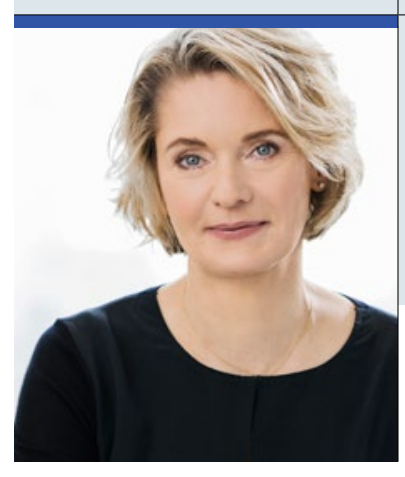

"Nun befinden wir uns an der Schwelle zu einer neuen

,Mab-Ära.' Ich glaube aber nicht, dass eine neue Substanzklasse

allein allheilend ist."

\section{Man kann der Migräne nicht davonlaufen}

$\mathrm{M}$ ittlerweile sind 38 Genorte mit 44 Genvarianten bekannt, die das Risiko erhöhen, mit Migräne zu reagieren.

In der Akuttherapie der Migräneattacke wird mit Triptanen die Wirkung von CGRP (Calcitonin-Gene-related peptide) gestoppt. Diese Substanzen haben das Leben vieler Migränepatienten seit den 1990er-Jahren revolutioniert.

Während traditionelle Prophylaktika zufällig ihre Wirksamkeit im Rahmen der Behandlung anderer Indikationen gezeigt haben, wurde nun erstmals eine Therapie spezifisch zur Migräneprophylaxe entwickelt. Die Antikörper interagieren mit einem Molekül, das spezifisch für Entzündungen, Sensitivierung und Schmerz im Migräneanfall ist, CGRP. Verabreicht man diese monoklonalen Antikörper, kann die Wirkung von CGRP für Wochen gestoppt und die Bereitschaft des Gehirns mit einer Migäneattacke zu reagieren, reduziert werden. Der Wirkeintritt ist innerhalb von wenigen Tagen zu erwarten; bei den bisher zu Verfügung stehenden Prophylaktika oft erst nach Monaten. Häufig wird die Adhärenz für eine Migräneprophylaxe durch die Nebenwirkungen der Substanzen limitiert.

Ende 2017 wurden im New England Journal of Medicine die Ergebnisse zweier Studien zur Wirksamkeit von Antikörpern gegen CGRP zur Vorbeugung der chronischen und episodischen Migräne publiziert (s. Seite 12). Die prophylaktische Gabe von Fremanezumab bei 1.130 Probanden reduziert signifikant die Anzahl der Kopfschmerztage pro Monat bei Patienten, die an chronischer Migräne leiden. Erenumab zeigte ebenfalls eine Attackenreduktion bei episodischer Migräne. Die Analyse der Daten zeigte auch, dass der Antikörper signifikant die Migränehäufigkeit, den Effekt der Migräne auf die täglichen Aktivitäten sowie die Notwendigkeit für die Anwendung von Migräneakutmedikamenten im Zeitraum von sechs Monaten reduziert.
Die Studien zeigen, dass die neue Substanzklasse bei einem Teil der Patienten eine klinische Wirkung entfaltet. Die Kopfschmerztage pro Monat reduzieren sich signifikant im Vergleich zu Placebo, entsprechen zum Teil aber den Ergebnissen anderer „traditioneller Migräneprophylaktika“. Zu erklären ist dieser Effekt dadurch, dass CGRP nur einer von mehreren Überträgerstoffen ist, die bei der Entstehung der Migräne bedeutsam sind. Aber: Migräneattacken können weiter auftreten. Es werden zudem "super responder" beschrieben, bei denen die Migräneattacken nahezu aufhören. Es fehlen aber Daten zu Langzeiteffekten. Auch ist unklar welchen Effekt die Blockade von CGRP auf andere Organe im Körper oder etwa beim Vorliegen kardiovaskulärer Komorbiditäten hat.

Generell bleibt aber die Perspektive, dass mehr Patienten ihre individuelle Belastung durch die Erkrankung reduzieren können. Denn nicht allein die Anzahl der Kopfschmerztage ist die eigentliche Belastung, sondern der Verlust der Fähigkeit durch die anfallsartig auftretende Erkrankung das eigene Leben planerisch sicher zu gestalten.

Gelegentlich stelle ich mir die Frage: War ich früher eine bessere Ärztin? Warum sind die Adhärenzraten für die Prophylaxe heute viel schlechter als in den 1980er-Jahren? Zum einen sicher durch die bessere, nebenwirkungsärmere Akuttherapie mit Triptanen, die die „Ergotamin-Ära" ablösten.

Nun befinden wir uns an der Schwelle zu einer neuen „Mab-Ära“. Ich glaube aber, dass eine neue Substanzklasse allein nicht ,allheilend" ist, sondern ein aktives Gestalten einer tragfähigen Arzt-Patient-Beziehung unter Einbeziehen der digitalen Medien und Berücksichtigung der Lebenssituation unendliche Chancen birgt.

Herzlich, Ihre

Astrid Gendolla 